\title{
Case Study: 3D Application of the Anatomical Method of Forensic Facial Reconstruction
}

\author{
Paloma Joana Galzi ${ }^{1 *}$ and Joe Mullins ${ }^{2}$ \\ ${ }^{1}$ Galzi Forensics Limited, London, UK \\ ${ }^{2}$ The National Center for Missing and Exploited Children, Virginia, USA
}

*Corresponding author: Paloma Joana Galzi, Forensic Imaging Specialist at Galzi Forensics Limited, London N5 1UZ, UK, Tel: +44 7539 466653; E-mail: paloma.galzi@gmail.com

Received date: September 23, 2016; Accepted date: November 16, 2016; Published date: November 21, 2016

Copyright: @ 2016 Galzi PJ, et al. This is an open-access article distributed under the terms of the Creative Commons Attribution License, which permits unrestricted use, distribution, and reproduction in any medium, provided the original author and source are credited.

\begin{abstract}
This article reports on techniques used in forensic facial identification with a 3D modeling software system to create a virtual sculpture. In this forensic case study, Free Form Modeling SensAble Technologies and a haptic feedback Phantom ${ }^{\circledR}$ Desktop ${ }^{T M}$ were used to reconstruct the facial features of the deceased from her skull. It was previously C-T scanned and then imported as an STL file under which the work was done. The advantages of the haptic feedback device is that the forensic specialist is able to "feel" the surface of the skull, not only to provide a more accurate assessment of the individual -such as their ancestry, sex and age determination-but also to visualize the process of the Manchester method of forensic facial reconstruction step by step.
\end{abstract}

Keywords: Facial imaging; Facial reconstruction; Forensic science; 3D modelling; Forensic science; Manchester method; Identification; Pennsylvania state police; NCMEC

\section{Case Background}

In 2015, the Pennsylvania State Police approached The National Center for Missing and Exploited Children (NCMEC) in Alexandria, Virginia, USA, as a last resort to identify remains from a cold case. The Forensic Imaging Unit at The National Center provides imaging services to law enforcement and families such as $2 \mathrm{D}$ and $3 \mathrm{D}$ facial reconstructions, post-mortem depictions and age progressions of missing and unidentified persons. In this case, the remains of a mixed race young female between the ages of 11 and 15 were due for a 3D forensic facial reconstruction. She had been found at a landfill in Westmoreland County in September 1967, and her case went cold for nearly 50 years.

\section{Introduction and Methodology}

The most important factor affecting the face is the underlying skeleton. The skull consists of 22 bones, and its shape will provide the different variations between each individuals. The anatomical method used here relies on virtually modeling every muscle of the face onto the skull.

\section{Anatomical method}

The anatomical method of facial reconstruction was developed by Gerasimov, a Russian anthropologist who was convinced that developing an anatomical approach involving modeling each facial muscle onto the skull before applying a layer of skin was more accurate for forensic purposes [1]. This method was later adapted and taught by Prag and Neave [2], Iscan and Helmer [3].

\section{Material}

We have used SensAble Technologies Freeform Modelling Plus System which includes the Phantom ${ }^{\circ}$ Desktop ${ }^{\text {mix }}$ haptic device. Once the skull is imported into the software, pieces can be moved, duplicated, reattached if need be (if the skull is partly damaged, or if the mandible has been scanned separately), much faster and quicker than when the remains are handled manually. The virtual technique of modelling with the haptic device allows the forensic imaging specialist to feel all the surfaces of the modelled skull that is being sculpted on screen, and to produce an intuitive interaction with the digital process [4]. The different objects imported and those sculpted into the software will be easily manipulated into different shapes in space, on a solid or seethrough plane for better accuracy and precision purposes [5]. This technique also provides important skeletal details for facial reconstruction such as position and measurements of different characteristics of the skull [6].

\section{Skull assessment: Ancestry, sex determination and age determination}

With access to the autopsy report, the crime scene report and the CT scan of the skull, the preliminary work can begin. From the anthropology report and the autopsy report, the ancestry of the deceased was established: Mixed race black and white person, which can be verified by variation traits observed on the skull by the forensic anthropologist and the imaging specialist [3,7]. The deceased was most likely a female due to nonmetric cranial traits of the skull [8]. From the same reports it was determined that the remains were very young from her dental assessment, probably between 11 and 15 at time of death [9].

\section{Pegging and modelling}

To estimate the thickness of the skin, tissue depth markers were used: they consist in little pegs positioned onto the skull at a 90 degree 
Citation: Galzi PJ, Mullins A (2016) Case Study: 3D Application of the Anatomical Method of Forensic Facial Reconstruction. J Forensic Res 7:

Page 2 of 4

angle to the bone surface on different anatomical point of the skull, called craniofacial landmarks (Figure 1). Here, the FBI 2015 tissue depth data was used, each one measured and positioned correctly. Guideline tangents are also positioned, as an indicator for the placement of the ears, eyes and nose (Figure 2).
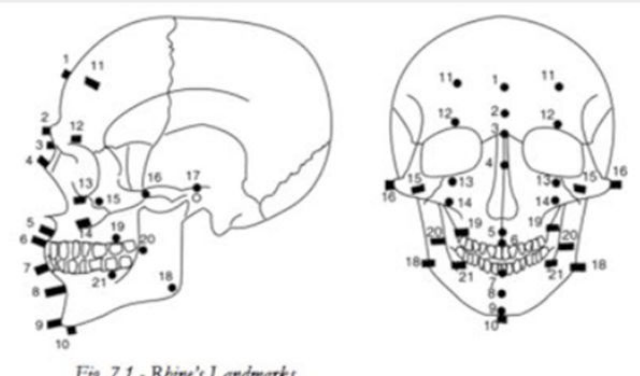

Fig. 7.1 - Rbine's Landmark

Figure 1: Craniofacial landmarks by rhine.

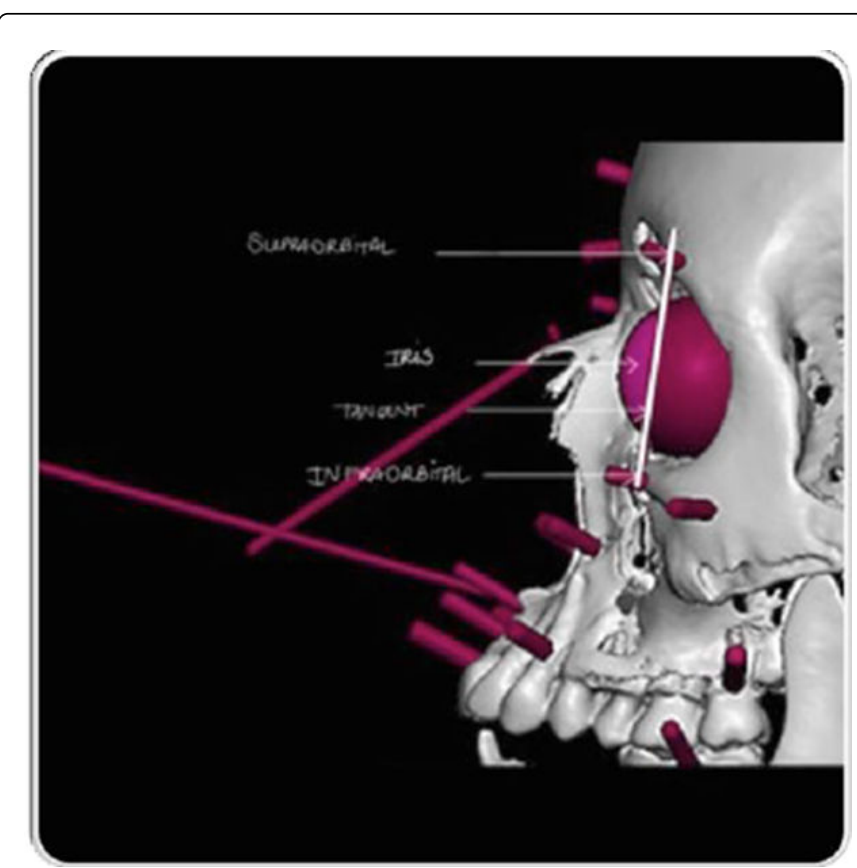

Figure 2: Guidelines (Galzi Forensics).

Modeling the muscles comes next. All the muscles, layer by layer, can be activated as see-through pieces (Figure 3) to be able to always rely and follow the shape of the bone for better accuracy.

Each muscle can also be mirrored and repositioned symmetrically and correctly on the other side of the skull, which saves time without damaging the remains as opposed to the manual method of reconstruction (Figure 4). The muscles, if sculpted on different layers, can be saved in a separate folder and be reused and modelled for other reconstruction cases [10].

Once all the muscles are positioned, the skin layer can be added and the facial features can be modelled, with the pegs as indicators of the soft tissue thickness [11]. The ears are modelled in reference to the mastoid process and the angle of the jaw, as outline by Taylor [12].

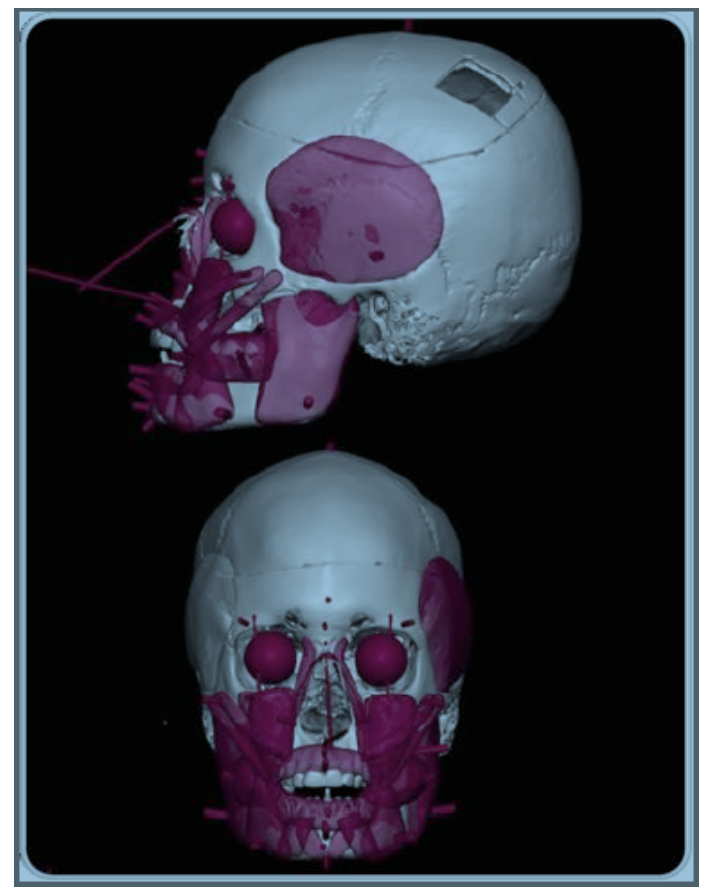

Figure 3: muscle structure with pegs (Galzi Forensics).

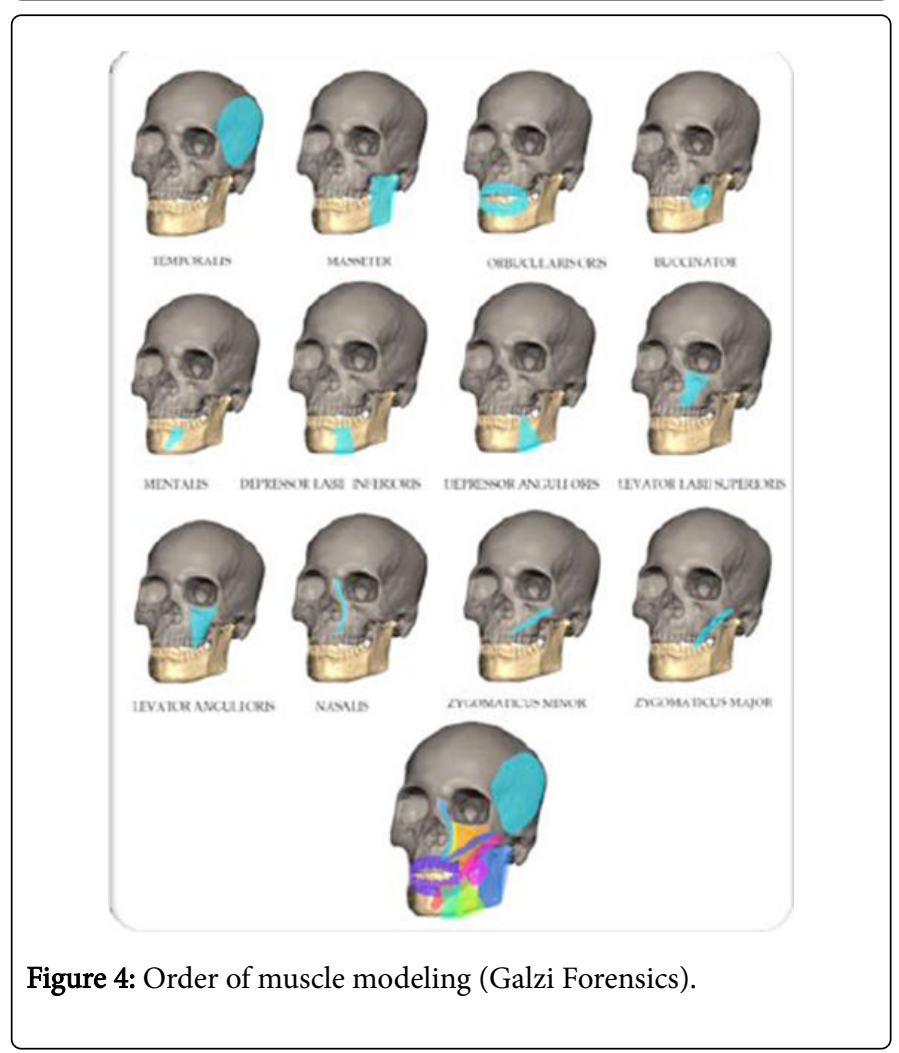

The lips are shaped one by one determined by the underlying structure of the bone in reference to the inter-canine distance, the 
height of the incisors, the occlusion of the teeth, the dental pattern and the shape of the jaw [4,5]. The lips and mouth can be reused and reshaped on future cases. The same will apply for the eyes and the nose, taking into consideration the markers as indicators for positioning the features: a theory stated that the inner and outer corner of the eyes was precisely determined respectively by the lacrimal fossa and the malar tubercle, often easy to find on the skull. The nose, buildup of nasal bones and cartilage, involves calculations of its shape based on the angle and width of the nasal aperture $[11,13]$ and slowly the face can appear. All of these modelled features are then easier to integrate to the system and to reuse at any given time.The hairstyle was done last: one of NCMEC's staff joined us in the Forensic Imaging Unit so we could scan her hairstyle, and then apply it to the facial reconstruction (Figure 4). The final step of the process was to create a realistic rendering through Adobe Photoshop of the facial reconstruction for law enforcement, so it could be published in the medias and trigger someone's memory. The final draft of the rendering (Figure 5) was made using different black and white images to compose a final one, and finally to be sent off to Law Enforcement and the media.

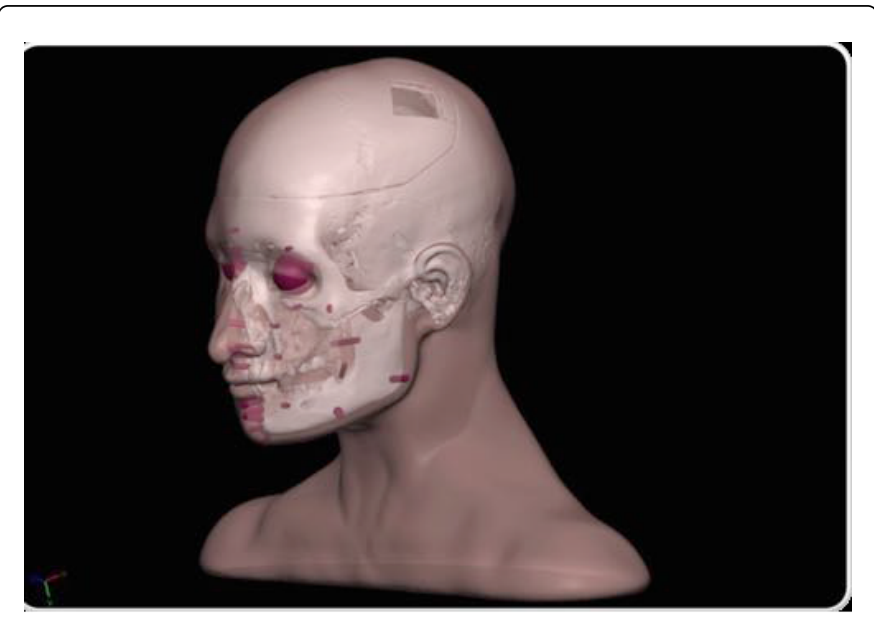

Figure 5: Modelling example of the facial reconstruction process (Freeform Modeling).

\section{Conclusion}

This method of facial reconstruction is efficient, accurate, and noninvasive to the remains, whether it is used for forensics or archaeological purposes. It is also significantly easier to remodel the missing persons face and quicker than the manual method using the anatomical method of reconstruction, but the practitioner should never lack training no matter the method. The fact that the reconstruction can then be processed through Abode Photoshop for a final rendering is also an improvement for Law Enforcement who requires sometimes more realistic portraits renderings of the missing.

In 2015 when the case was reopened, the remains were exhumed and the facial reconstruction was made at The National Center for the Missing and Exploited Children. The Thompson family believed that the remains were those of their missing loved one Teala Patricia Thompson, then 13-year-old when she went missing [14] (Figure 6). They provided Law Enforcement with DNA, and they were soon able to make a match. The little girl was finally identified, and the police are still asking for information leading to who killed Teala Thompson at this time [15].

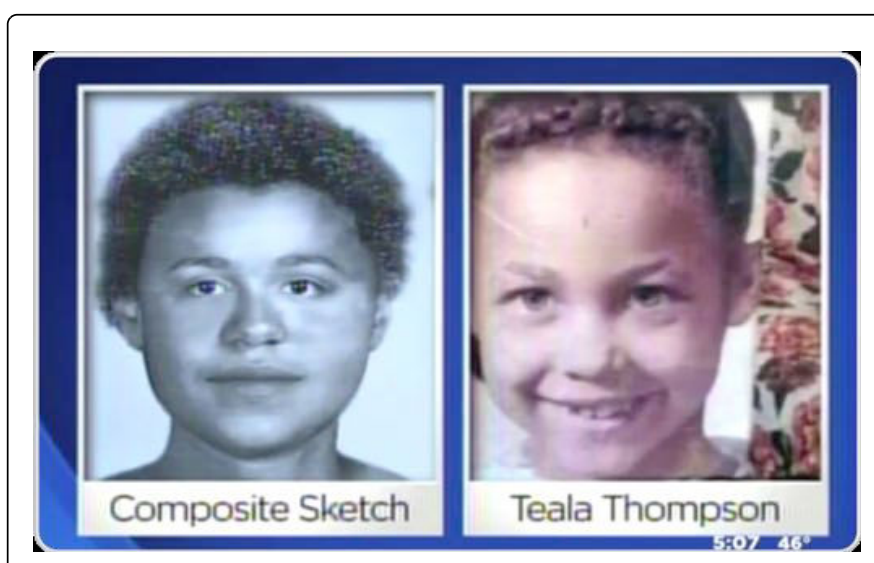

Figure 6: Reconstructed image and original image of Teala Thompson.

\section{Acknowledgement}

We would like to thank The National Center for Missing and Exploited Children team, the Pennsylvania State Police for the work on this case, Naomi Leach and Tatiana Del Parthogh for their help and support.

\section{References}

1. Kahler K, Haber J, Seidel H (2003) Re-animating the dead: Reconstruction of expressive faces from skull data. ACM TOG Conf Proc 22: 554-561.

2. Prag J, Neave R (1997) Making Faces: using forensic and archaeological evidence. Texas A \& M University Press, Texas, USA.

3. Iscan MY, Helmer RP (1993) Forensic Analysis of the Skull: Craniofacial Analysis, Reconstruction, and Identification. Wiley-Liss, New York, USA.

4. Wilkinson C, Rynn C (2012) Craniofacial Identification. Cambridge University Press, Cambridge, England.

5. Wilkinson C (2010) Facial reconstruction-anatomical art or artistic anatomy? J Anat 216: 235-250.

6. Turner W, Tu P, Kelliher T, Brown R (2006) Computer-aided forensics: facial reconstruction. Stud Health Technol Inform 119: 550-555.

7. Gerasimov MM (1955) The Reconstruction of the Face from the Basic Structure of the Skull.

8. Wheat A (2009) Assessing ancestry through nonmetric traits of the skull: A test of education and experience. MA Thesis: Graduate Council of Texas State University, Texas, USA.

9. Maureen S, Sue B, Louise S (2009) Juvenile Osteology: A Laboratory and Field Manual. Academic Press, London.

10. Wilkinson CM (2004) Facial anthropology and reconstruction. In: Thompson TJK, Black S, editors. Forensic Human Identification. CRC Press, Florida, USA.

11. Black S, Thompson T (2006) Forensic Human Identification - An Introduction. CRC Press, Florida, USA.

12. Taylor KT (2001) Forensic Art and Illustration. CRC Press, Florida, USA.

13. Rynn C, Wilkinson CM, Peters HL (2010) Prediction of nasal morphology from the skull. Forensic Sci Med Pathol 6: 20-34.

14. http://pittsburgh.cbslocal.com/2016/08/05/sister-of-victim-in-cold-casemystery-devastated-but-relieved-to-have-some-answers/

15. http://pittsburgh.cbslocal.com/2015/12/08/composite-sketch-released-ofremains-of-unidentified-teenager/ 